\title{
RADIOLOGICAL FEATURES OF ENLARGED BRONCHIAL
} ARTERIES

\author{
BY \\ MAURICE CAMPBELL AND FRANCES GARDNER
}

From the Cardiac Departments of Guy's Hospital and the Royal Free Hospital

Received December 3, 1949

Changes in the radiological appearances of the hilar region of the lungs may indicate that the pulmonary blood supply is not normal. - In atresia of the pulmonary valve, the pulmonary arteries may be absent, but more often they are small and may be supplied or supplemented by anomalous vessels. Then blood reaches the lungs mainly by the bronchial arteries or by other collaterals and there is little flow through the diminutive pulmonary arteries.

We wish to describe certain features of the X-ray films-both with intravenous injection of opaque substances and without this help-features that indicate an abnormal blood supply to the lungs by enlarged bronchial and collateral arteries. After a short account of present knowledge of the subject we shall discuss some teleradiograms with these unusual appearances. We shall then describe the angiocardiograms of some cases which we believe show that these collateral vessels are largely responsible for the abnormal vascular pattern.

We shall first consider two patients with anomalous pulmonary blood supply, one with a clinical diagnosis of truncus arteriosus and the other with pulmonary atresia or possibly truncus arteriosus where the diagnosis was supported by direct observation at operation. We shall then describe five other patients in whom the presence of hypertrophied bronchial arteries and pulmonary atresia was confirmed post-mortem.

\section{Present Views}

Pulmonary atresia and common arterial trunk are the two conditions in which bronchial arteries are likely to be seen.

Hypertrophy of these arteries as part of the collateral circulation has been known for a long time and was referred to by Chevers (1846) and Peacock (1858). Abbott (1932) describes the bronchial, mediastinal, and œsophageal arteries as an important source of collateral blood supply to the lungs in pulmonary atresia, and also the anomalous arteries arising from the subclavian, the thyroidea ima, and the aorta itself; and Brown (1939) refers to their occurrence in pulmonary atresia and occasionally in transposition. But except for their pathological anatomy little was known until recently. Danelius (1942) emphasized the absence of a hilar comma in a case of truncus arteriosus and looking at the X-ray afterwards thought it should have been possible to suspect the diagnosis before death.

Taussig (1947) points out that this absence of the hilar comma is seen also with pulmonary atresia. She discusses the importance of the bronchial arteries, particularly in cases of truncus arteriosus, and states that when they are much enlarged, providing the main circulation to the lungs, they may cause the aortic arch to be fuzzy and indistinct. This can be seen in her Fig. 79, 83, and 88 , and in the original illustration of Danelius (1942). The bronchial arteries may also indent the œsophagus or cause it to deviate from its normal course, and more emphasis is placed on this as evidence of their enlargement than on changes in the aortic outline.

Taussig thinks that when the circulation to the lungs is by way of bronchial or anomalous vessels 
the lungs are remarkably clear, but that in contrast, when the posterior mediastinal vessels are greatly enlarged, the hilar shadows are exaggerated. She thinks that pulmonary atresia rarely leads to much development of the bronchial arteries because the ductus arteriosus, being patent in fotal life, discourages their hypertrophy at this early stage: but this is not borne out by our cases.

\section{Radiological ApPearances}

In normal teleradiograms the descending branches of the right and left pulmonary arteries are seen as gently curved structures, concave towards the mid-line and running downwards and slightly outwards from the lung hila. They are well known to everyone though relatively little has been written about them except in the recent papers of Appleton (1944) and Lodge (1946). On the right this branch of the pulmonary artery often lies entirely outside the heart shadow. Its lateral margin may, however, coincide with or lie entirely within the right auricular contour and in these circumstances it can only be recognized in the more penetrating films. On the left, the upper part of the descending pulmonary artery frequently contributes to the middle cardiac segment but the lower part generally lies entirely behind the heart shadow.

In patients with the tetralogy of Fallot the normal anatomy of the pulmonary arteries can usually be recognized in teleradiograms of the chest. The pulmonary artery shadows may look small, or
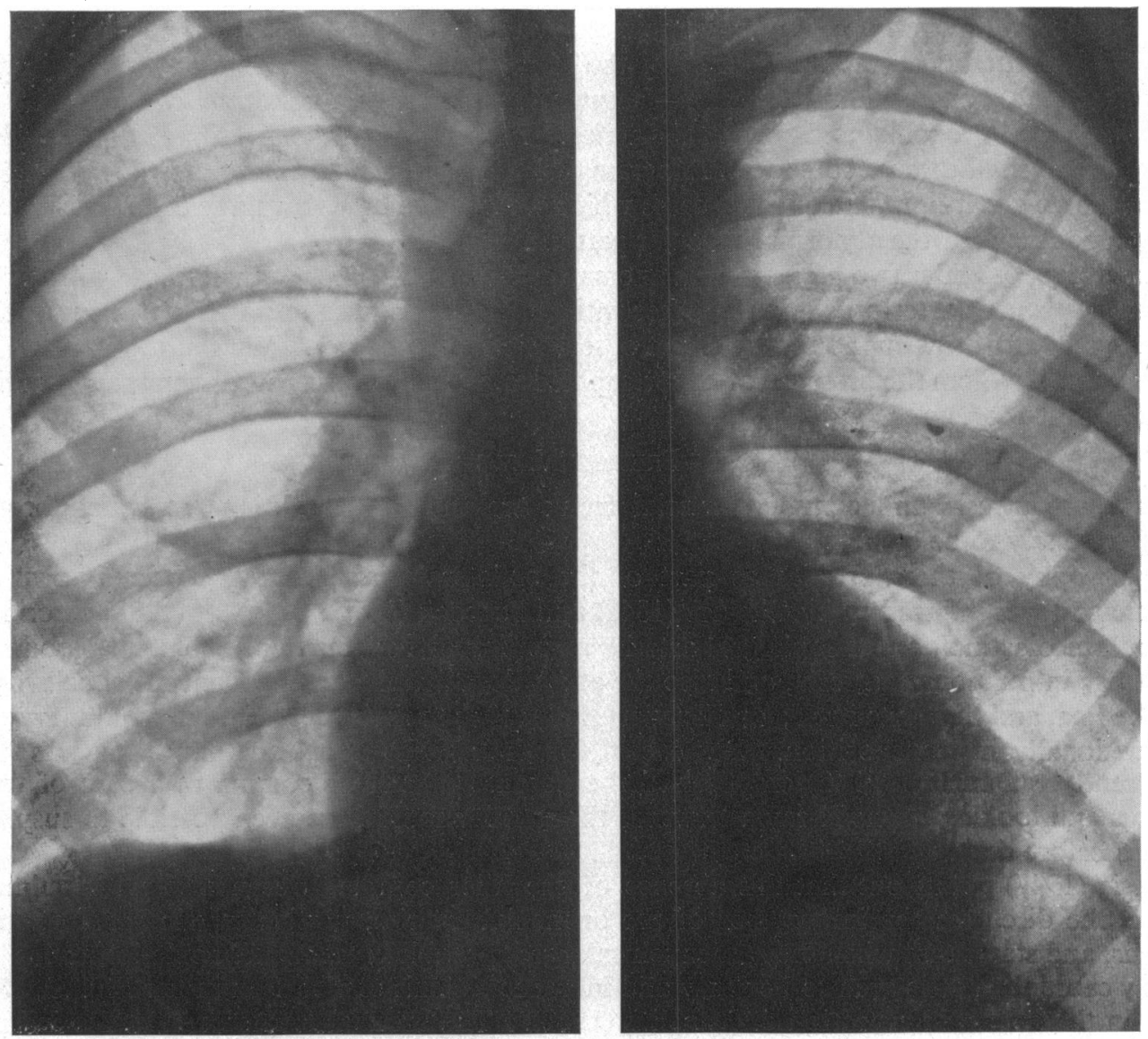

FIG. 1.-Teleradiogram from a patient with Fallot's tetralogy showing right and left pulmonary arteries. Although the arteries are small they have the same general features as normal, and the smooth downward curve can be seen on both sides. 
may sometimes be more irregular than normally. Fig. 1 shows the descending branches of both pulmonary arteries: their normal outline is clearly seen, though they are smaller than usual and obviously carry little blood, as the lung fields look unusually light. After a successful subclavian-pulmonary anastomosis the artery became larger and the lung fields denser.

Fig. 2 shows the right hilar region from two other patients with Fallot's tetralogy, the first

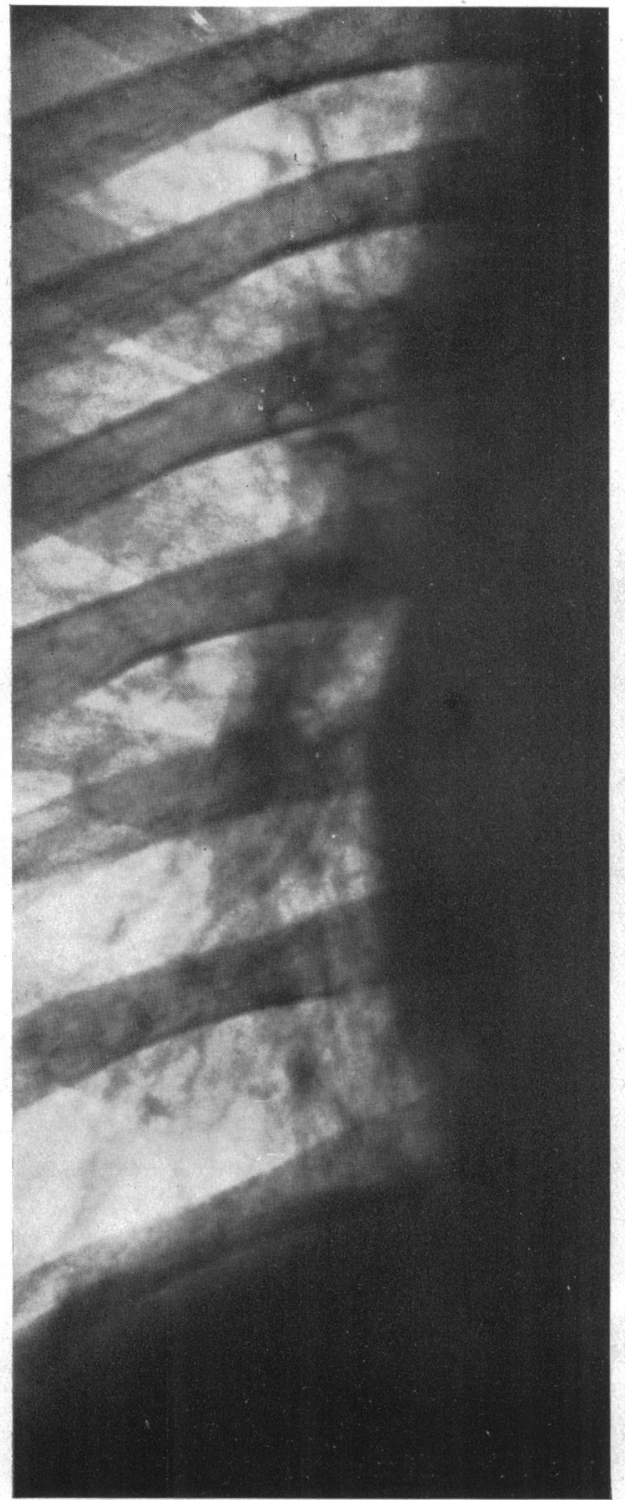

A

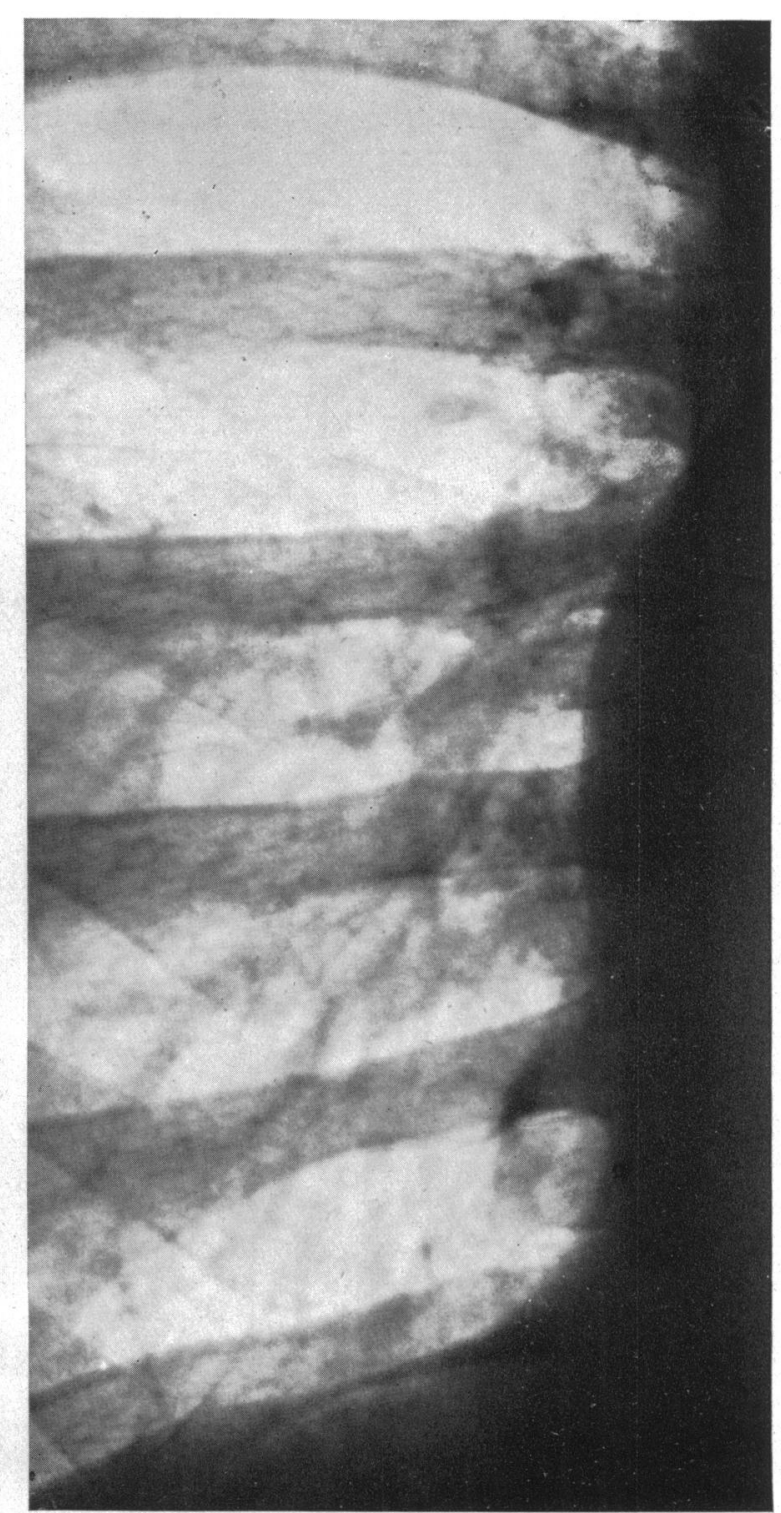

B

Fig. 2.-The right pulmonary artery from two patients with Fallot's tetralogy.

(A) The descending branch of the right pulmonary artery is fairly well seen; there is some branching but rather less than normally and the pattern in the lung fields is not quite usual and suggests some anastomoses. The general density of the lung fields is diminished, especially in the lower part.

(B) The shadow of the descending branch of the right pulmonary artery is less well seen and more irregular, and the branches seem small and somewhat unusual. The density of the lung fields is diminished, especially in the upper part. 
showing a small but normal pulmonary artery with light lung fields, and the second showing a fainter and more irregular shadow from a patient where the pulmonary blood flow was greatly diminished.

Absence of these curved vascular shadows and the presence of the abnormal shadows to be described are the radiological features that suggest a bronchial artery blood supply to the lungs because of pulmonary atresia or truncus arteriosus. On the left these abnormal shadows are rounded and nodular and do not seem to connect directly with the outline of the heart; sometimes they are directed outwards and upwards in place of the smooth downward curve of the left pulmonary artery and its descending branch. On the right there may be a rather diffuse mottled mass of collateral vessels, spreading much higher than the normal position of the right pulmonary artery because the bronchial arteries often descend from the under surface of the aortic arch. Both these features were present in most of our patients and even the attenuated hilar comma in Case 5 (Fig. 13) and the co-existence of abnormal anastomoses to the small pulmonary artery in Cases 2, 4, and 6 (Fig. 7, 11, and 14) did not mask the characteristic appearances.

With angiocardiography the bronchial arteries are seen filling later than the aorta. They

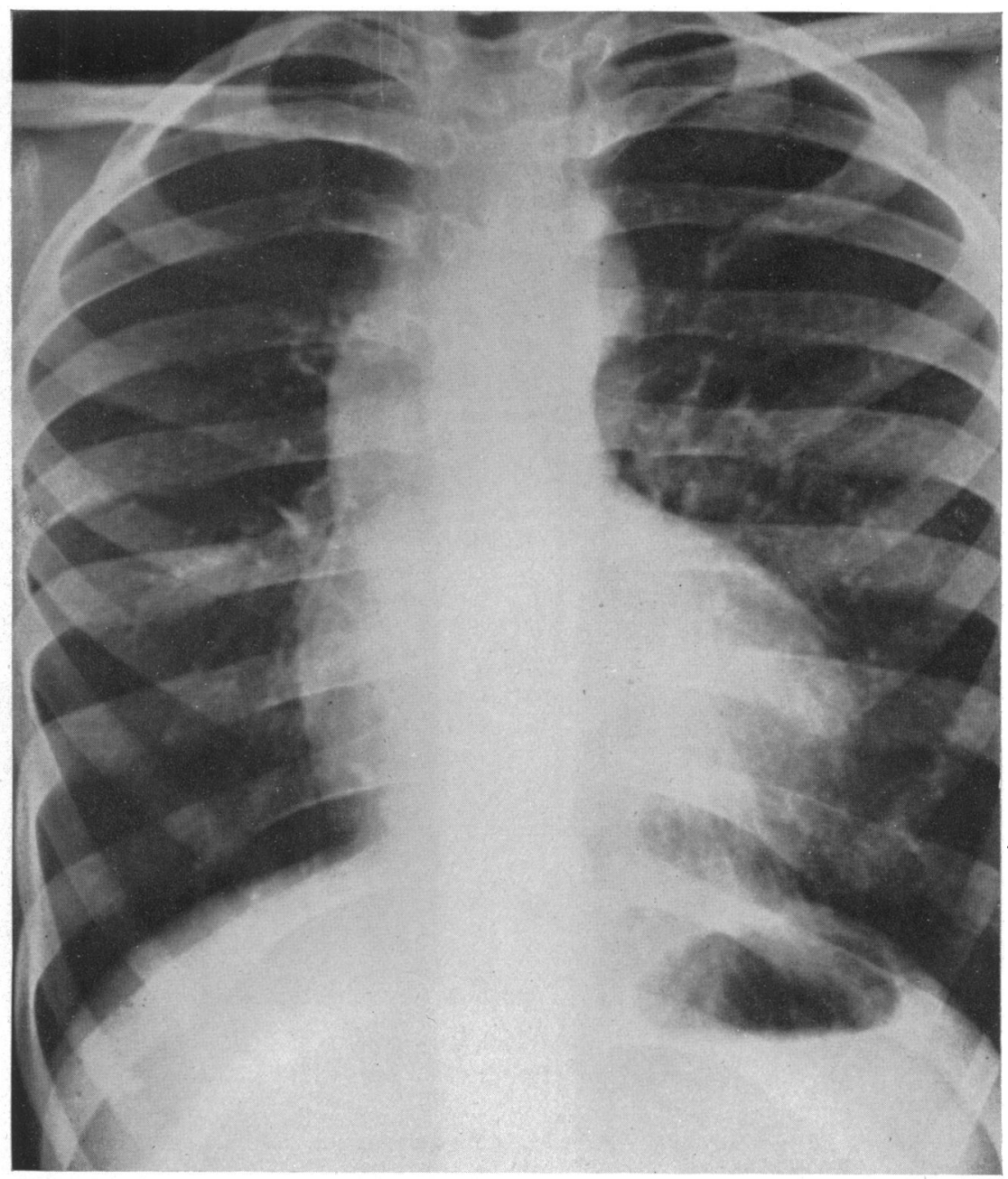

FIG. 3.-Teleradiogram from a child with truncus arteriosus. The normal hilar vascular shadows are absent. 
arise from the under surface of the arch or from the descending aorta and fill up to some extent the aortic window before they spread widely around the hilum of the lung. Even with diodone they are difficult to define precisely. The antero-posterior angiocardiograms show that they fill only after the ascending aorta (Fig. 9, 12, and 13) but this may be difficult to demonstrate unless rapid multiple exposures are made. It is in the lateral and left oblique positions (Fig. 4, 10, and 16) that they are most easily recognized. Here the bronchial arteries are seen as dense shadows lying behind the ascending aorta with rather straight branches spread out fanwise in the lung fields.

The first examples (Fig. 3 and 4) are from a cyanotic child, aged 10 years: there was a continuous murmur best heard on the left side behind and the clinical diagnosis was persistent truncus arteriosus

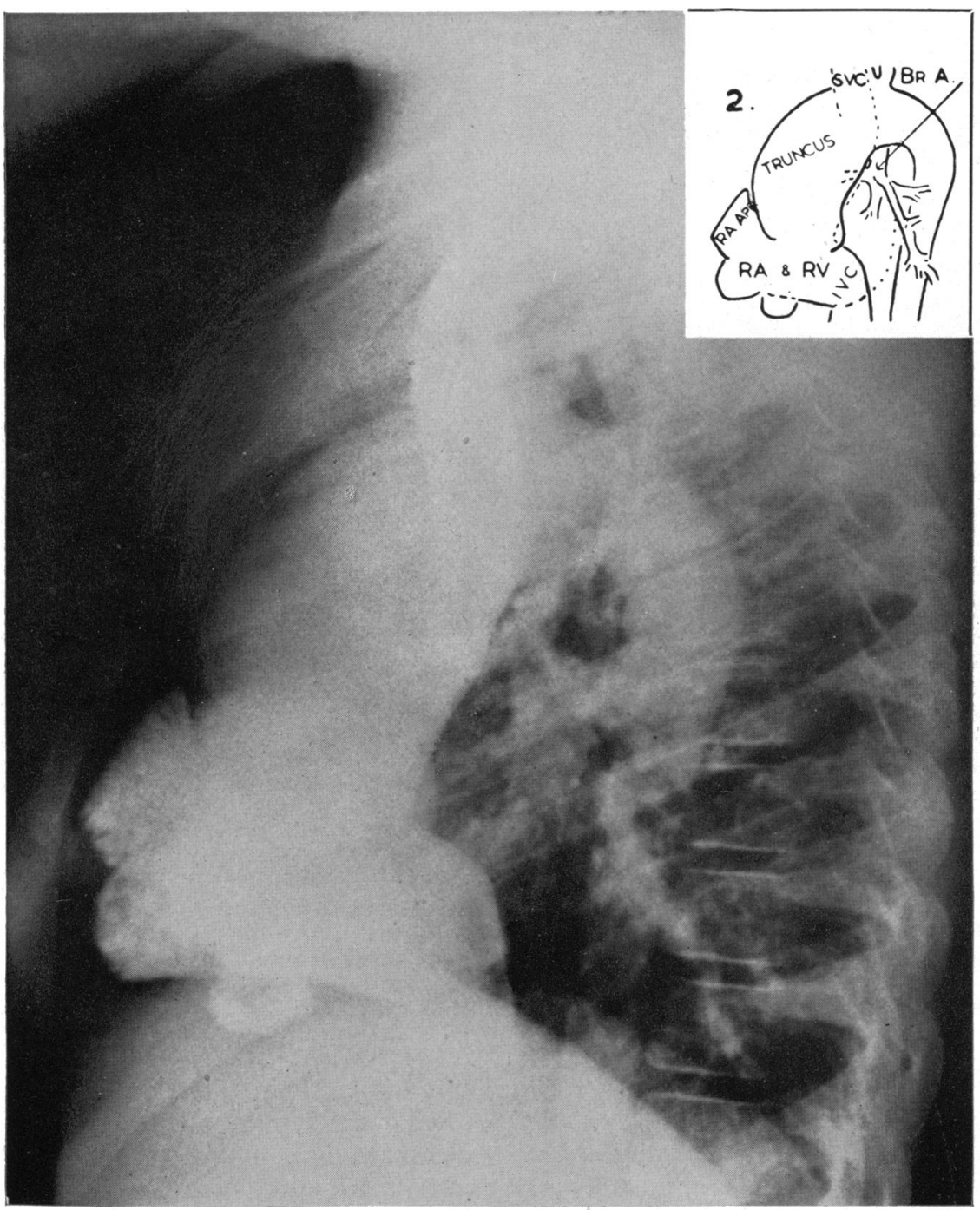

Fig. 4.-Angiocardiogram in the left lateral position from the same child as Fig. 3. At 2 sec. the right auricle and the appendage, the right ventricle, the large common trunk, and the arch are well seen. From the concavity of the arch and from the descending aorta, large tortuous vessels that are hypertrophied bronchial arteries pass to the hilum, and spread out in the lung fields. 
with bronchial artery blood supply to the lungs. The teleradiogram (Fig. 3) shows the wide aortic arch and the boot-shaped heart with a deep pulmonary bay. The lung fields are translucent and there are no shadows resembling normal pulmonary arteries. The vascular structures in the lung hila consist of numerous narrow vessels irregularly arranged, and on the left side it is clear that they are not continuous with the cardiac contour.

The angiocardiograms confirm the presence of a common arterial trunk and the absence of pulmonary arteries. In the left lateral position (Fig. 4) dense vascular shadows arising from the concavity of the aortic arch run downwards towards the hila and are distributed in the lung fields. These structures are, we believe, the hypertrophied superior bronchial arteries which, in this instance, are largely responsible for the pulmonary circulation.

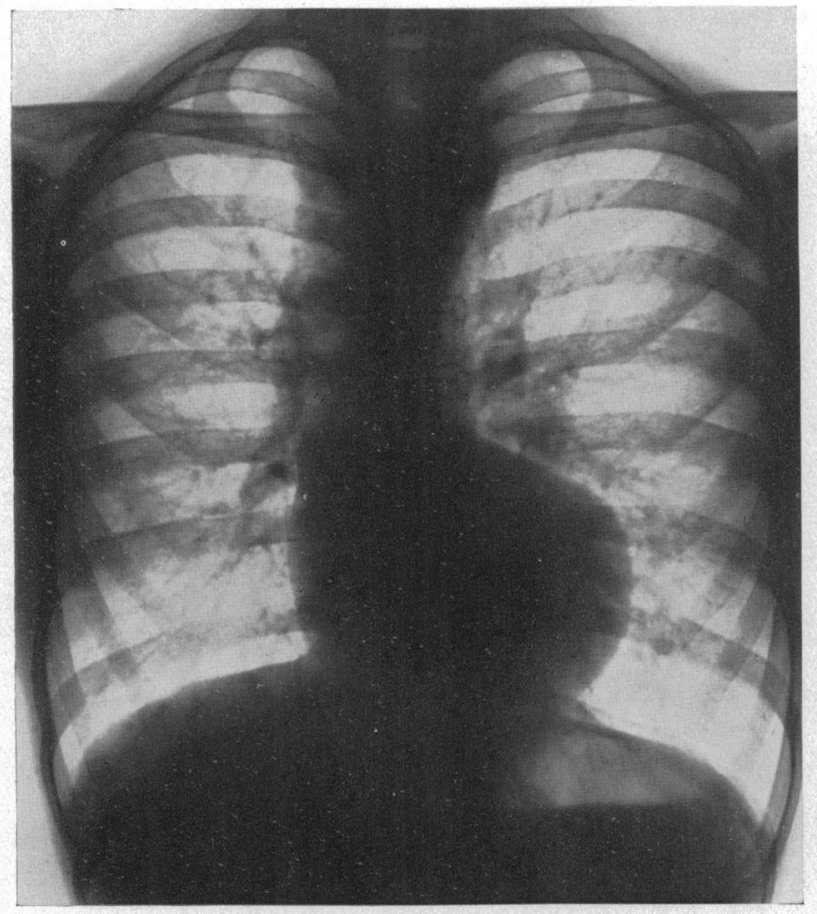

A

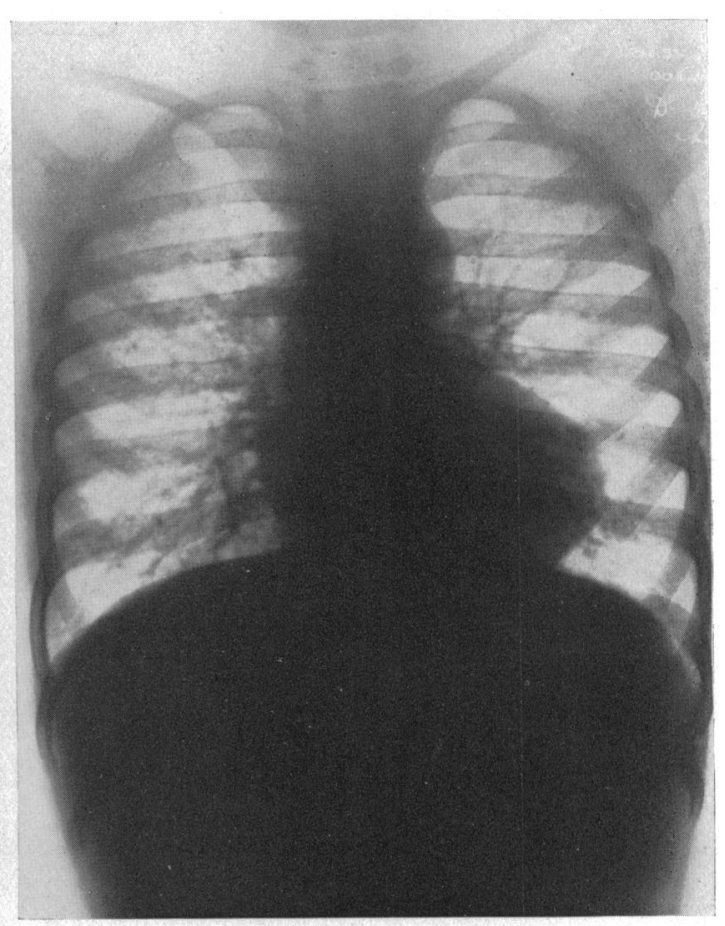

B

FIG. 5.-Reduced teleradiograms of hypertrophied bronchial arteries in pulmonary atresia.

(A) In the left pulmonary region there are isolated nodular shadows instead of the hilar comma; on the right there is a mottled irregular appearance spreading high up. Case 0087.

(B) Absence of main pulmonary arteries on both sides with numerous smaller bronchial arteries, providing a mottled appearance with rather linear branches. The linear spread is characteristic but otherwise the picture is less typical than Fig. 5A and 6. For detailed description see Fig. 11. Case 4.

Fig. 5 shows the teleradiograms of two further cases and larger pictures of the pertinent parts of the lung fields are shown in Fig. 6 and 11. Fig. 5A and 6 are from a boy, aged 14, with moderate cyanosis and disability from infancy and a continuous murmur in the second left space: the final diagnosis was pulmonary atresia, or possibly truncus arteriosus, with a bronchial artery blood supply to the lungs. The teleradiogram (Fig. 6) is characteristic, with an unusually deep pulmonary bay so that the spine shows through, and with no visible pulmonary arteries. On the left there are two large nodular shadows that do not seem to connect directly with the heart and on angiocardiography fill after the aorta. On the right there is a curved shadow (marked with 


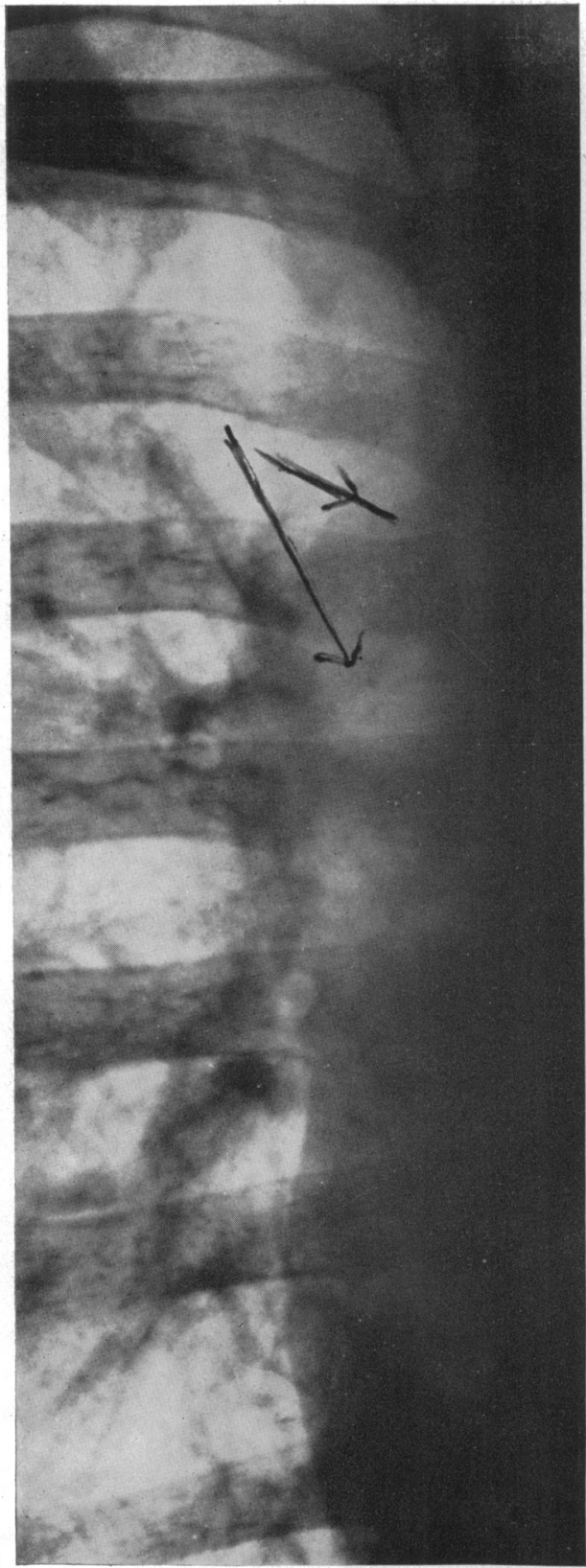

A

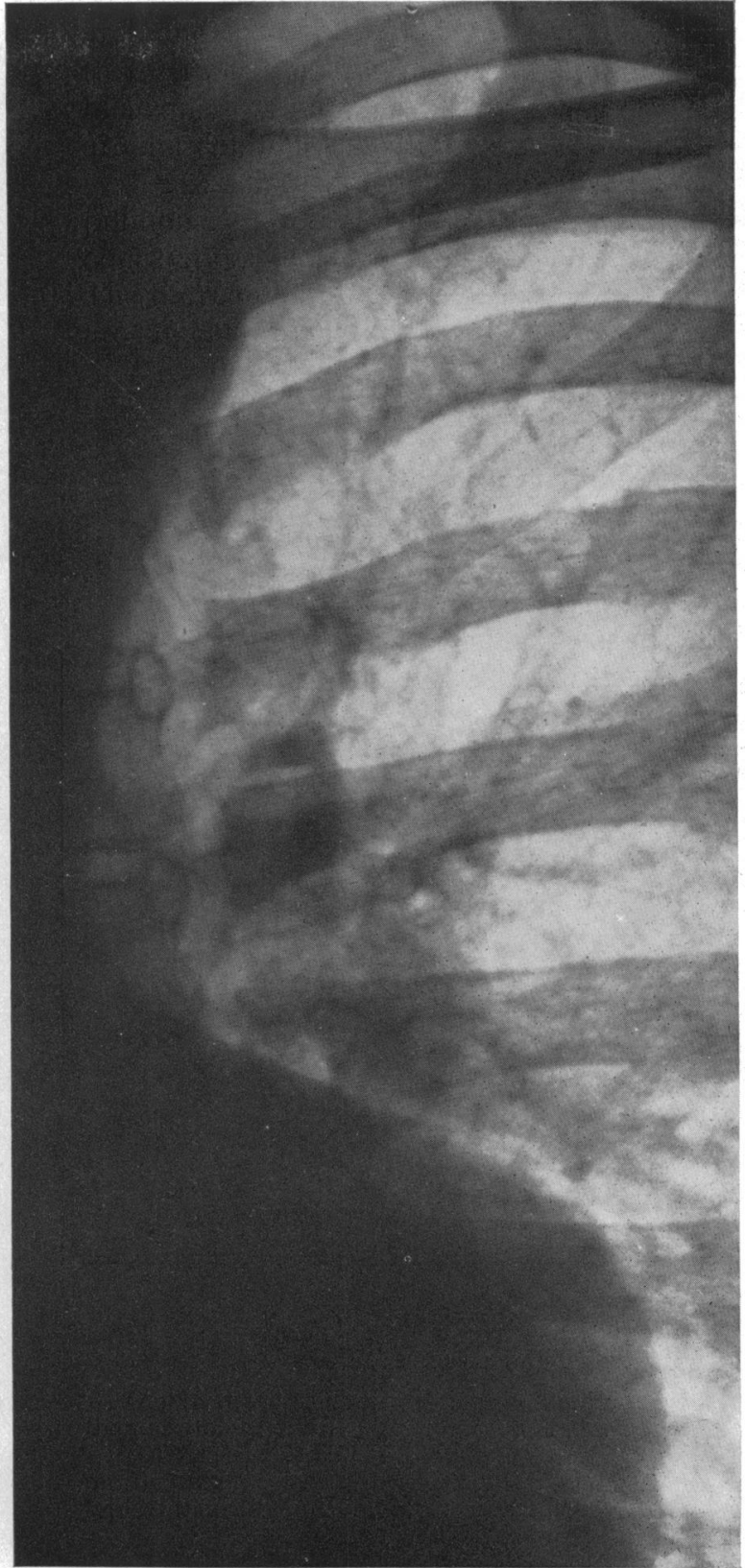

B

FIG. 6.-Natural-size view of the right and left hilar regions. The central part of the heart shadow and the outer parts of the lung fields have been cut off to show the pertinent parts on a larger scale. See Fig. 5A.

(A) Absence of the normal right pulmonary artery shadow. At operation no pulmonary artery could be seen, and a vessel (marked with arrows) was seen running down behind the S.V.C. and entering the lung root.

(B) A characteristic picture of the " nodular" appearance when bronchial and other collateral arteries replace the normal left pulmonary artery. Case 0087. 
arrows) running downwards behind the superior vena cava and dividing into several branches near the hilum of the lung. The angiocardiograms of this case have already been published (Campbell and Hills, 1950, Fig. 12).

Operation was advised with the hope of finding a vessel that would be adequate for an anastomosis, but none was found. Mr. R. C. Brock's report of his findings was as follows. No pulmonary artery could be found. There seemed to be a single trunk from the aortic arch that gave rise to the right subclavian, common carotid and a third artery, about $1 \mathrm{~cm}$. in diameter, that ran upwards and then downwards behind the superior vena cava and entered the hilum of the right lung. No thrill was felt. The artery, which seemed to have a systemic blood pressure, lay in direct contact with the lower part of the trachea and the right main bronchus.

These two patients are still alive and in good health, but the presence of demonstrable bronchial arteries appears to us to be in no doubt. In the five case reports that follow, the presence of bronchial arteries was suggested by the teleradiograms and confirmed by the comparison of these with the angiocardiograms, and was proved by the post-mortem examination.

\section{CASE REPORTS}

These five patients had atresia of the pulmonary valve, though the artery itself was always present, reduced in size and sometimes greatly so. There was always hypertrophy of the right ventricle, a high ventricular septal defect of the same type as that found in Fallot's tetralogy, and an aorta that

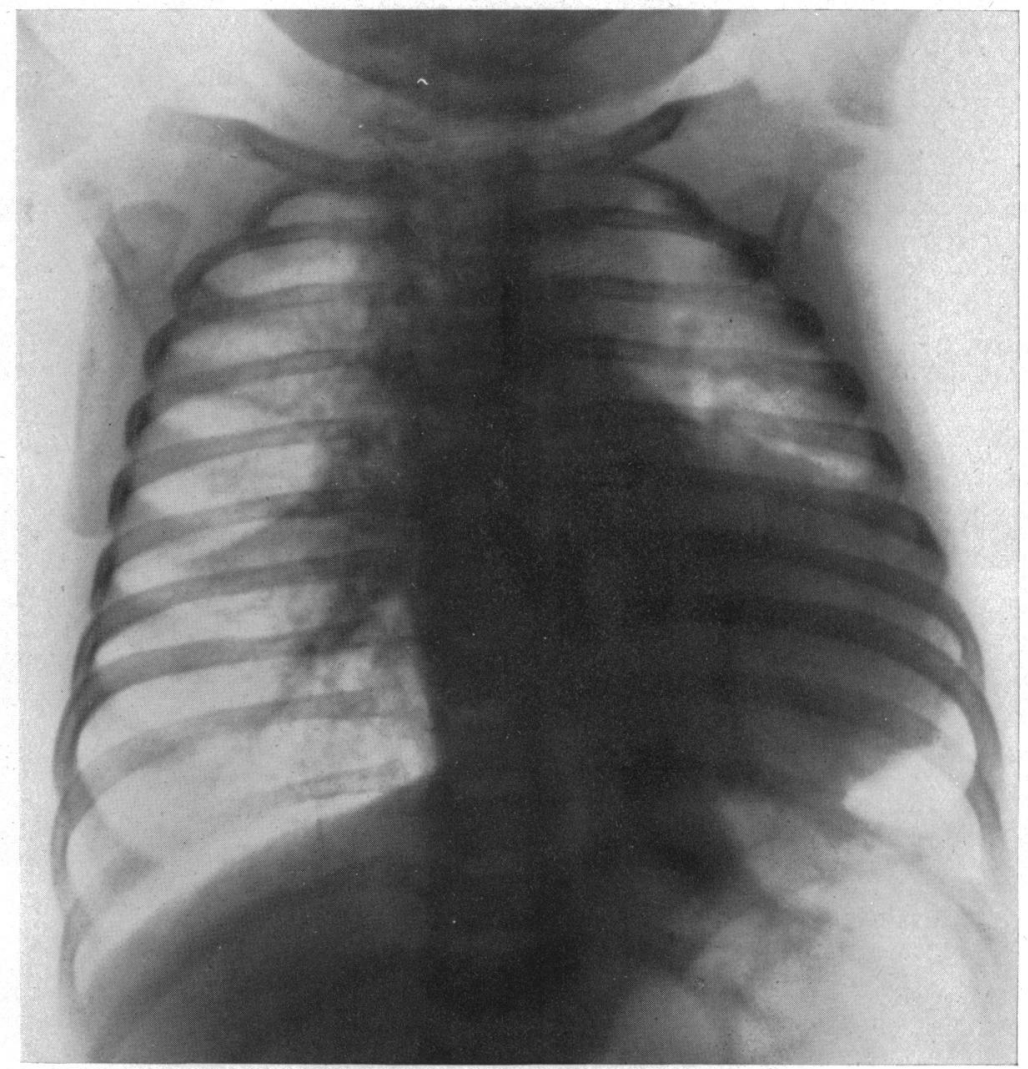

Fig. 7.-Radiogram from Case 2, an infant with pulmonary atresia. Massive shadows on the upper right side represent the main area of hypertrophied bronchial arteries and other collaterals. Owing to the enlargement of the heart, the vascular shadows cannot be seen on the left side. 
over-rode this defect. Full clinical notes and the pathological anatomy are being described (Allanby, Brinton, Campbell, and Gardner, 1950), so will only be given very shortly here in so far as they are revelant.

Case 2* (Reference No. OA19). S.N., died when four months old and no detailed diagnosis was made. The radiogram shows dense shadows on the right side (Fig. 7) which spread upwards above the normal position of the pulmonary artery.

Post-mortem, there was pulmonary atresia and the right-sided shadows seemed to be due to a large bronchial artery arising from the postero-inferior aspect of the arch of the aorta and passing just below the right main bronchus and behind the right pulmonary artery. Another bronchial artery ran along the upper edge of the right bronchus. A third ran into the hilum of the left lung and anastomosed with the left pulmonary artery.

Even after her death in 1948 we were puzzled by these unusual X-ray appearances in a case where

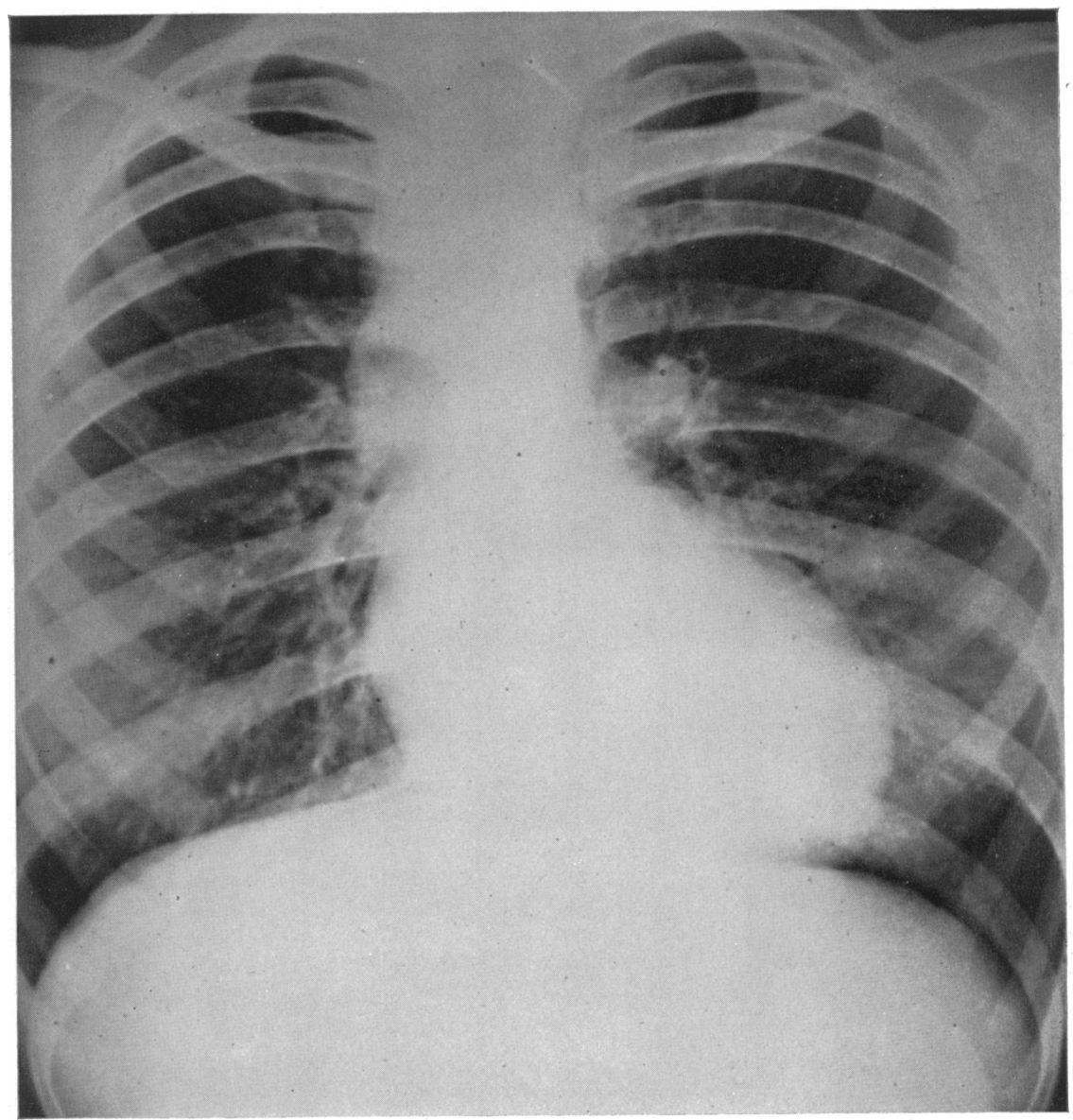

FIG. 8.-Teleradiogram from Case 3, a girl with pulmonary atresia and hypertrophied bronchial arteries. The shadows of the pulmonary arteries are absent. There is a nodular shadow in the left hilum and the vascular pedicle is broadened by abnormal collateral vessels high up on the right.

* Cases 1-6 have been given the same case numbers as in the paper by Allanby et al. (1950) to facilitate comparisons. Case 1 had pulmonary atresia with no ventricular septal defect and the circulation was maintained through a patent foramen ovale and a patent ductus arteriosus without enlargement of the bronchial arteries, so is not pertinent to the present discussion. 
the blood flow to the lungs was obviously diminished. It is only the experience of the subsequent cases that has revealed the true explanation.

Case 3 (Reference No. O187). S.R., a girl, aged 12, had severe cyanosis and moderately severe disability. The clinical diagnosis was pulmonary atresia and bronchial artery blood supply to the lungs. The teleradiogram (Fig. 8) shows a sabot-shaped heart with a moderate pulmonary bay and a right-sided aortic arch. The hilar vessels are abnormal in configuration-they extend very high on the right side, forming a lateral bulge to the vascular pedicle-and the characteristic comma appearance of the descending branch of the right pulmonary artery is absent. On the left, the vascular shadows have a nodular appearance but separation from the heart shadow is not complete.

In angiocardiograms in the antero-posterior position the aortic arch is filled at two seconds but the hilar vessels are not seen till the third second (Fig. 9). In the left lateral position the right auricle

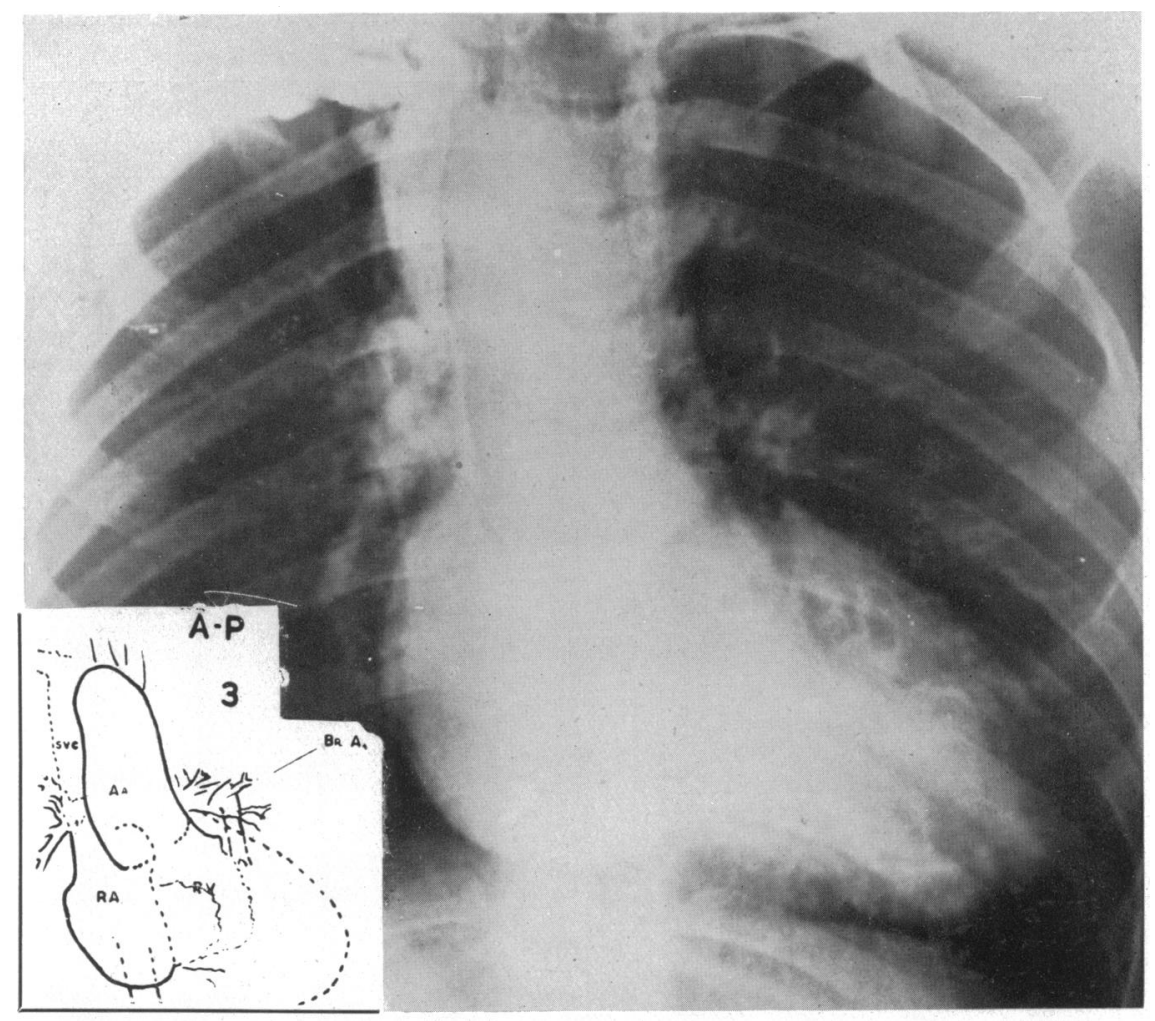

Fig. 9.-Angiocardiogram at $3 \mathrm{sec}$. in artero-posterior position from Case 3. There is diodone in the ascending and descending aorta and slight filling of the bronchial arteries. There are no visible pulmonary arteries.

and ventricle and the aorta contain diodone at two seconds and ill-defined vascular shadows are seen behind the ascending aorta. In the three-second film (Fig. 10) these abnormal vessels are more obvious; their branches are unusually straight and they spread out fanwise in the lung fields. In no film is there any evidence of the pulmonary artery or its branches.

Post-mortem, the infundibulum was narrowed and there was pulmonary valvular atresia. The pulmonary artery was very narrow, $3 \mathrm{~mm}$. in diameter, but patent beyond the valve. The circulation to the lungs was provided by two large bronchial arteries, arising from the concavity of the aortic arch and running close to the two main bronchi. From the upper part of the descending aorta there were many arteries which formed a free anastomosis round the osophagus and at the reflection of the pleura before turning into the lungs. 


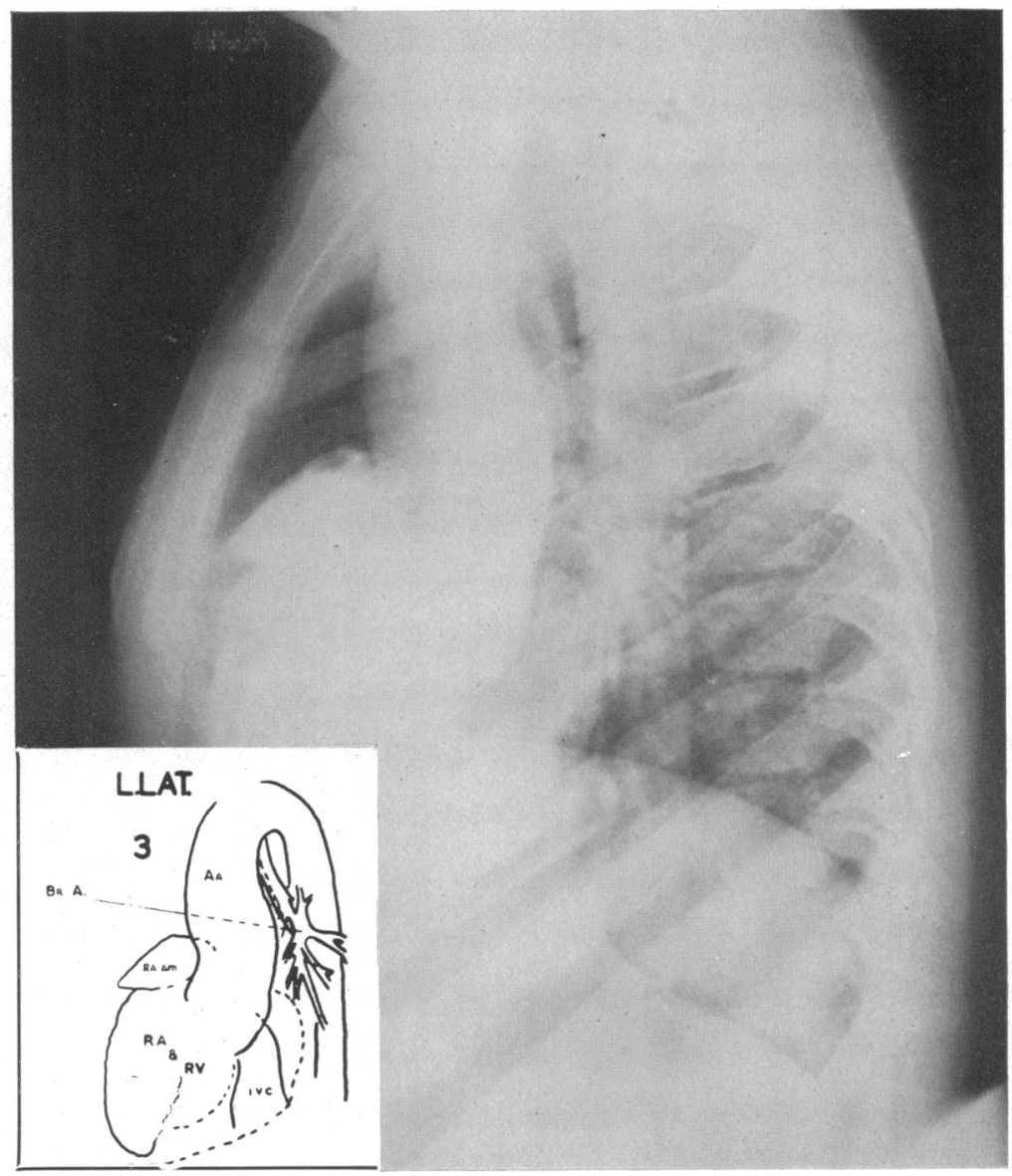

FIG. 10.-Angiocardiogram at $3 \mathrm{sec}$. in the left lateral position from Case 3. The aorta is filled with diodone and bronchial arteries descend from the concavity of the arch and spread into the lung fields.

Case 4 (Reference No. P048). A.F., a girl, aged 8, was cyanosed and could only walk 50 yards. The teleradiogram is shown in Fig. 5B and 11. On the right side the descending branch of the pulmonary artery is seen but in addition there are narrow straight shadows that do not conform to the normal pattern of pulmonary arterial branching (Lodge, 1946). On the left no pulmonary artery can be seen but there are dense nodular shadows with narrow straight branches spreading into the lung fields.

The angiocardiogram at two seconds shows filling of the large overriding aorta and its branches without any filling of the lungs. By the third second the upper zone of the right lung is filling well in a curious way, and at the bottom of this shadow there is something that might be a small pulmonary artery filling through an anastomosis. By the fourth second this is clearer (Fig. 12) and the lungs are becoming denser and can be seen to be filling on the left as well as on the right. The right lung appears to have a better blood supply than the left and this was confirmed at necropsy.

Post-mortem, there was severe pulmonary valvular stenosis amounting to a functional atresia, as only a fine probe could be passed. The pulmonary trunk was very small with a diameter of $2 \mathrm{~mm}$. but the main branches were almost normal in size. There were three large bronchial arteries (the two larger to the right and the third to the left lung) which received reinforcement from other anastomoses. The upper two accompanied the main bronchi and one anastomosed with the right 
pulmonary artery; the lower ran down behind the æsophagus and passed to the lower lobe of the right lung. The total calibre of these must have been much larger than that of the pulmonary artery. There were many small arteries arising from the aorta at the site of the intercostals.

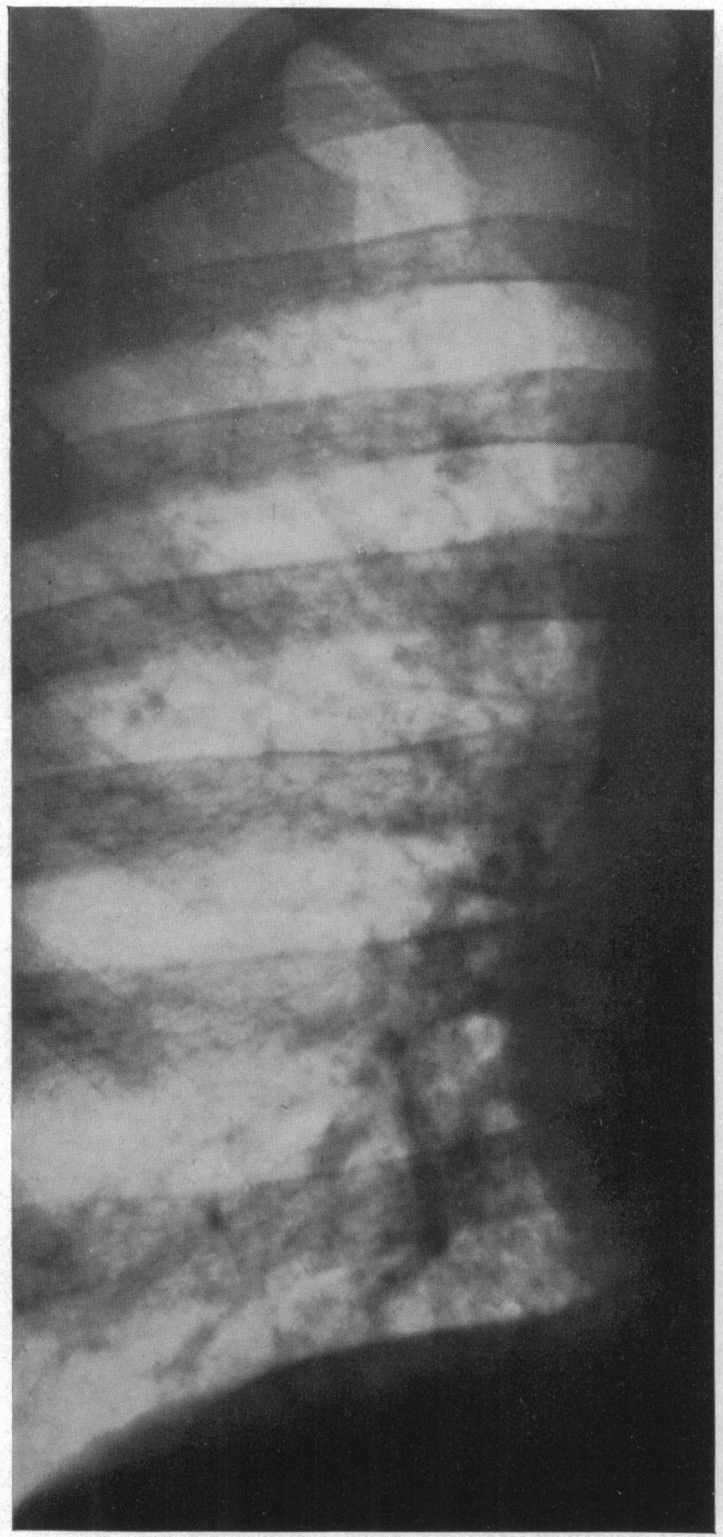

A

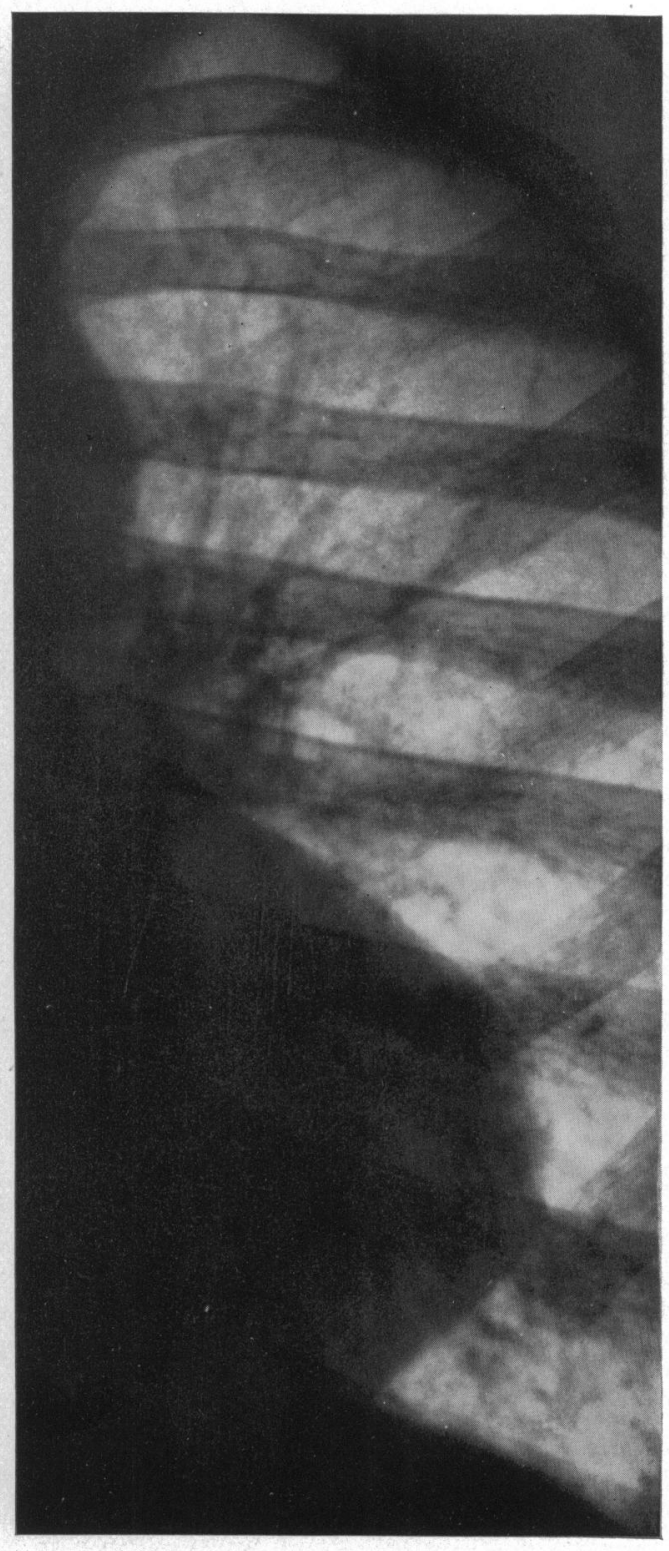

B

FIG. 11.-Natural-size view of the left and right hilar regions. Absence of pulmonary arteries on both sides. Case 4, see Fig. 5B.

(A) There is general mottling in the hilum and in the lower part some better defined small vessels that appear to cross each other rather than to divide like a normal pulmonary artery. Possibly the shadow above this may represent a small poorly filled pulmonary artery, but above it the shadows are anomalous and resemble collateral vessels.

(B) On the left side there are rounded mottled shadows but less distinct than in Fig. 6, and linear branches spreading upward from them. 


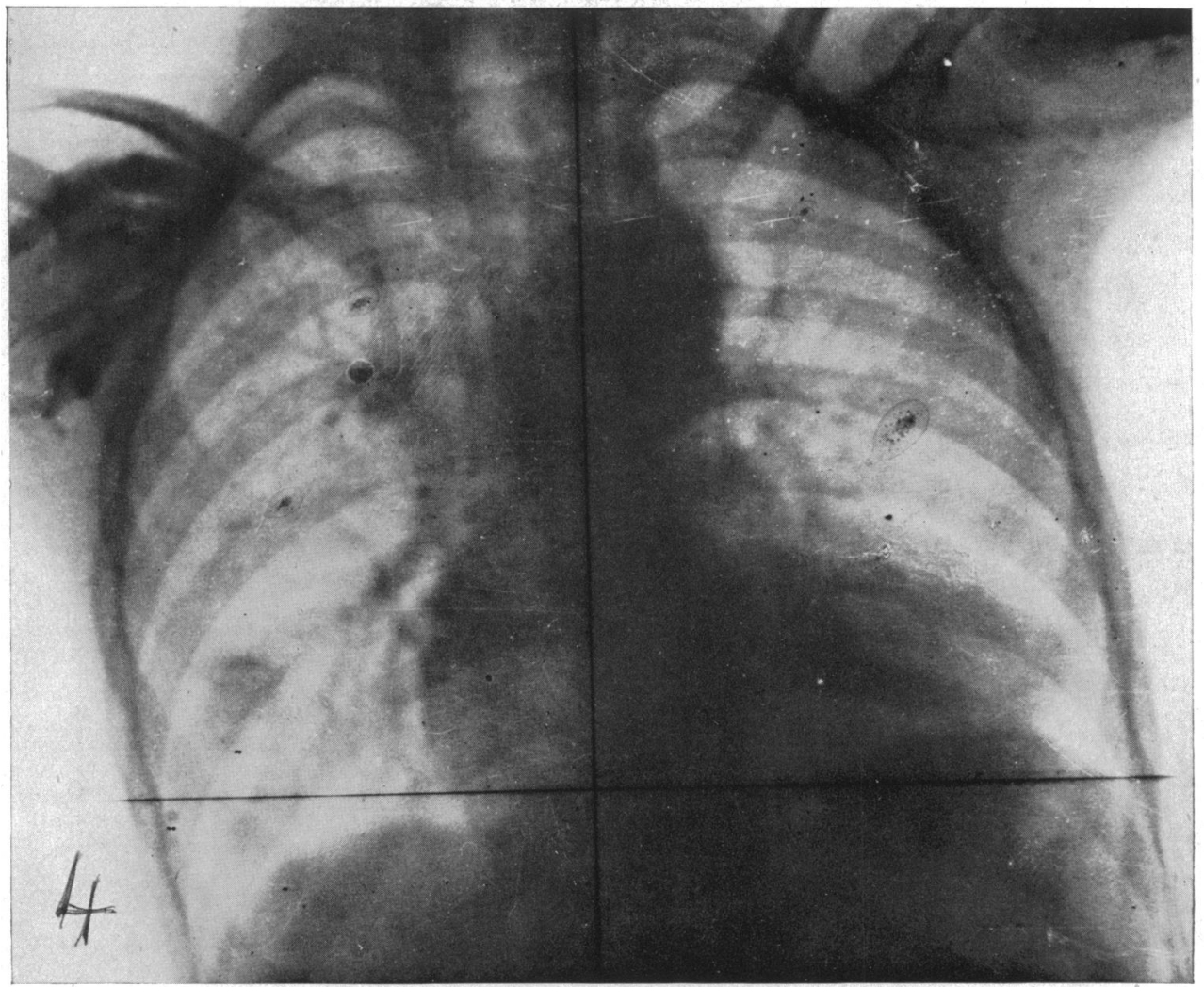

FIG. 12.-Angiocardiogram at $4 \mathrm{sec}$. from Case 4, a girl with pulmonary atresia. The teleradiogram has been shown in Fig. 5B and 11. In the right hilum there is a broad crescent-shaped shadow, the lower part of which probably represents a small and normally placed pulmonary artery, and the upper part, which seems responsible for the main filling of the lungs, the hypertrophied bronchial arteries. These filled sometime after the aorta. The left side is also beginning to fill in an irregular manner. There was an anastomosis between a bronchial and the right pulmonary artery.

Case 5 (Reference No. O016). J.N., a boy, aged 5, was more like a case of Fallot's tetralogy and pulmonary atresia was not suspected at first. He was the least cyanosed of these patients but could only walk 100 yards. The teleradiogram (Fig. 13A) shows a somewhat diminished blood supply to the lungs and a small pulmonary artery on the right, but no left pulmonary artery could be seen in the pulmonary bay. In the right upper zone there are dense vascular shadows resembling those seen in Case 2.

Angiocardiography shows filling of an overriding aorta at two seconds. At three seconds, and more so at five seconds, the lung fields are becoming opaque but no main pulmonary arteries are seen and the right upper zone shows more density than the rest of the lung. These appearances suggest pulmonary atresia with the lungs filling through dilated bronchial or collateral arteries (Fig. 13B).

Post-mortem, the pulmonary valve was represented by an atresic diaphragm; a dimple, too narrow for any probe, must just have been patent as water could seep through it. The pulmonary artery and its branches were small and the diameter was $6 \mathrm{~mm}$. compared with $13 \mathrm{~mm}$. for the aorta. There was moderate hypertrophy of only one bronchial artery and little of the intercostal arteries so that it seems difficult to understand how the child maintained even his limited activity; probably other collateral vessels were divided on removing the heart. 


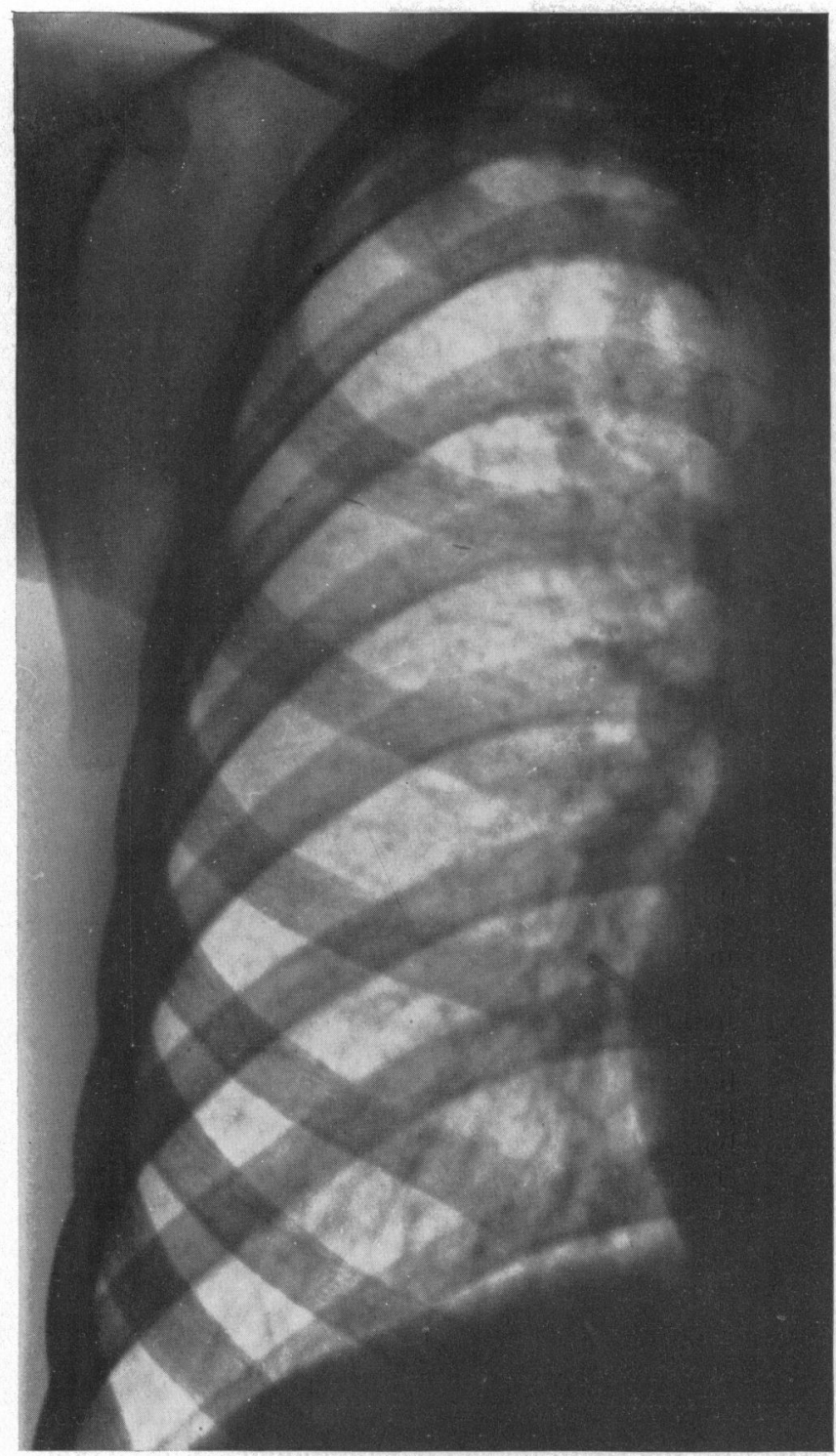

A
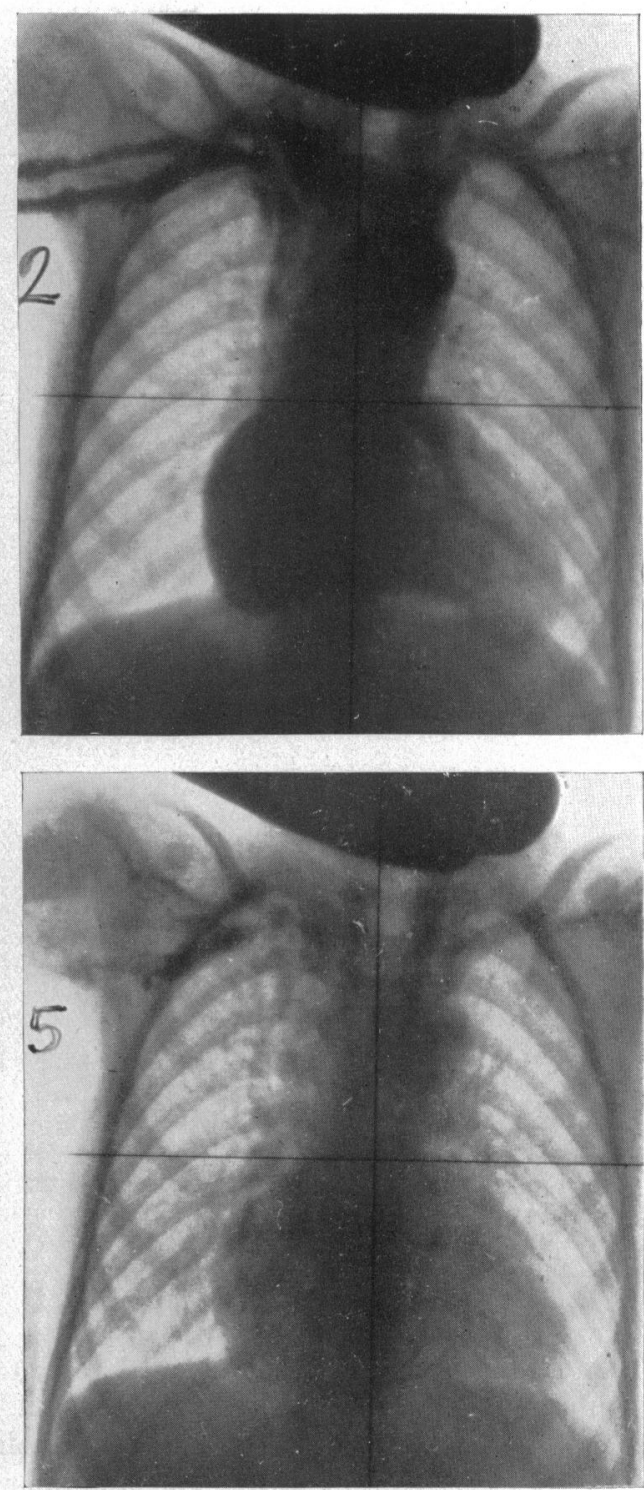

B

FIG. 13.-From Case 5, a boy with pulmonary atresia.

(A) Teleradiogram of the hilum of the right lung showing the diminutive pulmonary artery, and higher up other anomalous shadows that represent collateral circulation.

(B) Two angiocardiograms from the same patient. The upper at $2 \mathrm{sec}$. shows an over-riding aorta well outlined and behind the heart the small left pulmonary artery but no filling of the lungs. The lower, at 5 sec., shows the anomalous vessels, especially in the right upper zone, filling from the aorta.

Case 6. J.E., a girl, aged 7, was cyanosed and could only walk about a quarter of a mile slowly. She had a continuous murmur over the left upper chest. The clinical diagnosis was extreme pulmonary stenosis or atresia and persistent patency of the ductus arteriosus. The teleradiogram (Fig. 14) shows a sabot-shaped heart with a fairly deep pulmonary bay. The pulmonary vascular markings are abnormal: on the right the descending branch of the small pulmonary artery is seen 


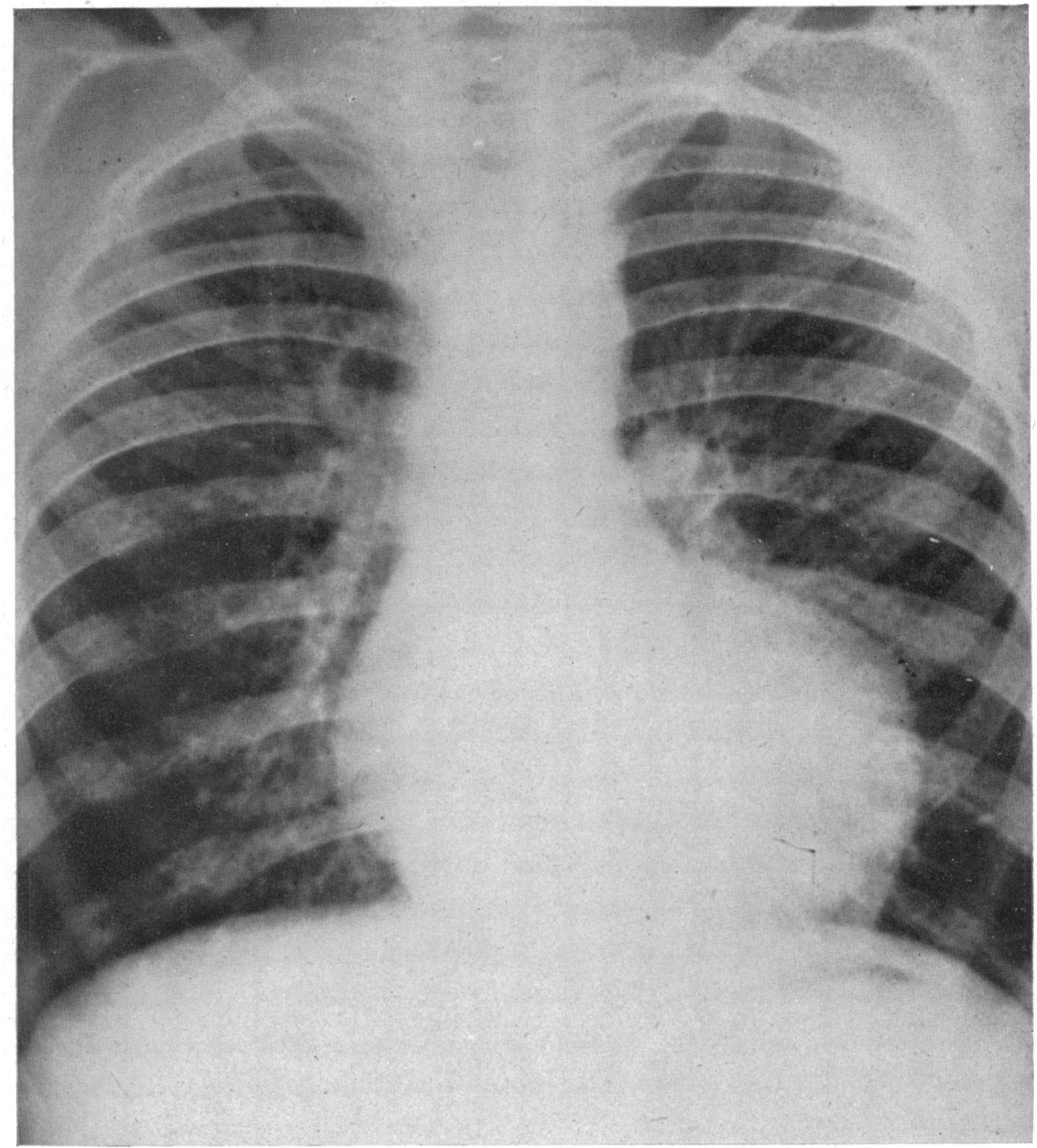

FIG. 14.-Teleradiogram from Case 6, a girl with pulmonary atresia, showing sabot-shaped heart with nodular vascular shadows in the left hilum.

but the vascular shadows extend higher than usual; on the left there are dense nodular shaped vessels at the hilum; on both sides the attenuation of the vascular markings towards the periphery of the lung fields is easily seen.

Angiocardiograms in the antero-posterior position show the aorta and great vessels filled at two seconds and the small pulmonary artery and its left branch indistinctly outlined (Fig. 15). In the left lateral position (Fig. 16) the film taken at two seconds shows the main pulmonary artery overlying the aorta, and dense ill-defined vascular shadows are seen beneath the arch and partially obscuring the aortic window. In the L.A.O. position the outline of the pulmonary artery is seen at two seconds and in addition the origin of the right branch of the pulmonary artery shows as a dense rounded shadow lying behind the ascending aorta.

Post-mortem, the infundibulum of the right ventricle was minute and ended bluntly in the fused pulmonary valves. The pulmonary trunk was thin walled and its diameter less than one-quarter that of the aorta: the left and right branches were also small and thin walled. Three large bronchial arteries arose from the inferior aspect of the arch of the aorta; one passed to the right and two to the left hilum of the lung. An anomalous artery arising from a coronary sinus opened into the main 


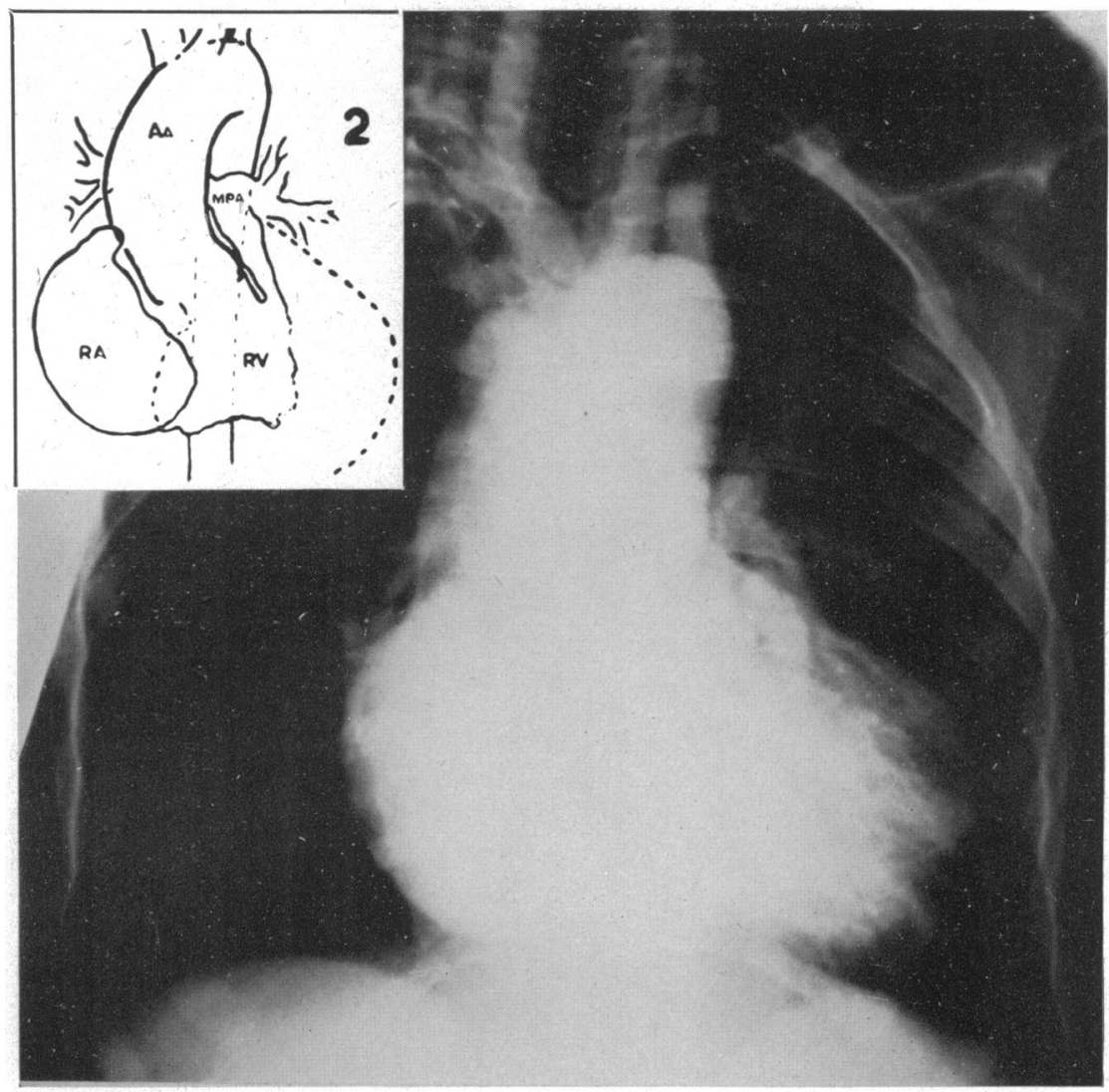

Fig. 15.-Angiocardiogram at 2 sec. in A-P position, from Case 6. Diodone is present in the right auricle and ventricle and the over-riding aorta. The tiny pulmonary trunk (that filled from an anomalous vessel) and its left branch are faintly outlined.

pulmonary trunk immediately distal to the fused pulmonary valves. The ductus arteriosus was closed so it was presumably this anomalous artery that was responsible for the continuous murmur.

\section{DiscUSSION}

The radiological appearances of enlarged bronchial arteries and other collateral vessels probably take many bizarre forms. We have attempted to describe those with which we have become familiar and we are confident that these can be recognized in teleradiograms. When the collateral circulation to the lungs is responsible for only a small part of the pulmonary blood flow and is therefore only slightly increased, a hilar comma may be present and recognition of the anomalous vessels may be more difficult. In these circumstances even angiocardiograms may fail to establish their presence with certainty.

Other collateral arteries, as well as the enlarged bronchial arteries, may perhaps be responsible for the abnormal shadows we have described, though post-mortem evidence suggests that the nodular shadows generally represent the latter. The distinction is, however, largely academic and has little bearing on clinical diagnosis or therapeutic procedures.

The significance of continuous murmurs in patients with cyanotic congenital heart disease is of interest. Three of our patients had such continuous murmurs, often best heard at sites that would be unusual for a patent ductus arteriosus. In the first with truncus arteriosus there was no proof of 


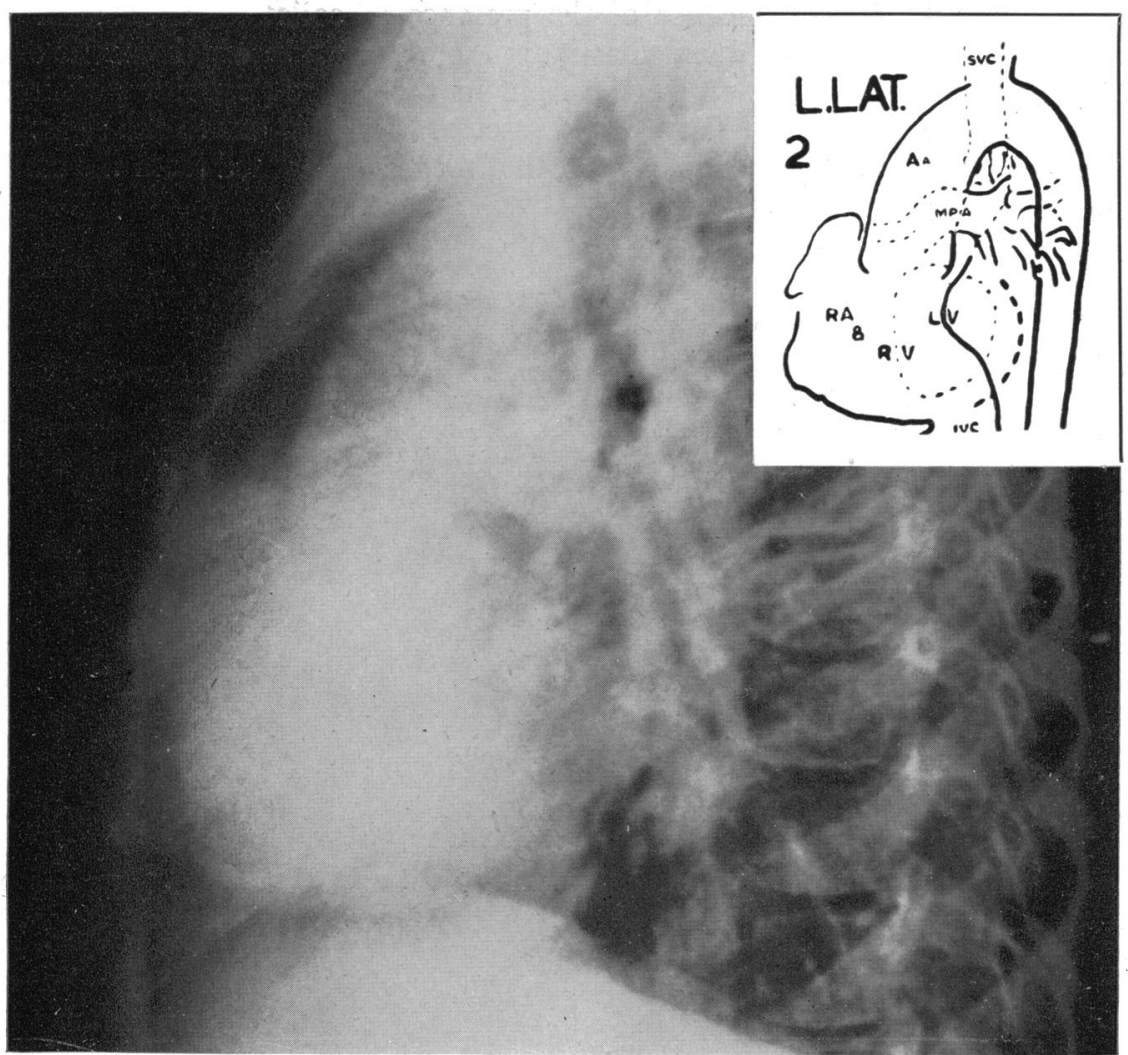

FIG. 16.-Angiocardiogram at 2 sec. in the left lateral position from Case 6. The film shows the pulmonary trunk overlying the aorta, and bronchial arteries in the concavity of the aortic arch. The small vessels in the lung fields that are abnormally straight and narrow are the branches of the bronchial artery.

where it was produced. In the second, there was a large bronchial artery, but again no proof that it was produced here. In Case 6, the continuous murmur heard on the left in front was probably due to the anomalous collateral artery: at operation, however, a continuous thrill was felt in the large bronchial artery, running into the right lung.*

\section{SUMMARY}

The radiological appearances of enlarged bronchial and collateral arteries are described in seven patients. In the first, the presence of these arteries rests only on clinical and radiological evidence; in the second, similar evidence is supported by the findings at operation. In the five other patients the teleradiograms showed anomalous pulmonary vascular markings; enlarged bronchial arteries and in some instances other collateral arteries were found post-mortem.

Absence of the hilar comma and a deep rounded pulmonary bay, often unusually sharply marked, suggest an anomalous pulmonary blood supply.

Dense vascular shadows, high in the mediastinum and nodular hilar structures with abnormal

* We have seen 25 cyanotic cases with such continuous murmurs and hope to deal with their causation more fully, but we think they are produced most often in enlarged bronchial or other collateral arteries in cases of truncus arteriosus or pulmonary atresia. Sometimes, but much less often, they are due to a true patent ductus arteriosus in cases of pulmonary atresia or Fallot's tralogy. 
branching in the lung fields are evidence of the presence of collateral circulation and enlarged bronchial arteries. The changes in the mediastinum are best seen below the aortic arch in the left anterior oblique position and high up on the right in the antero-posterior position where they broaden the pedicle of the heart and show dense vascular markings out to the right. On the left, rounded nodular shadows in the pulmonary bay, that may be separated from the cardiac contour, are characteristic of enlarged bronchial arteries.

\section{REFERENCES}

Abbott, M. E. (1932). Nelson's Loose-leaf Living Medicine, Vol. IV.

Allanby, K. D., Brinton, W. D., Campbell, M., and Gardner, F. (1950). Guy's Hosp. Rep. (In the press.) Appleton, A. B. (1944). Lancet, 2, 592.

Brown, J. W. (1939). Congenital Heart Disease, London.

Campbell, M., and Hills, T. H. (1950). Brit. Heart J., 12, 65.

Chevers, N. (1846). London med. Gaz. New series, 3, 282.

Danelius, G. (1942). Amer. J. Roentgen., 47, 870.

Lodge, T. (1946). Brit. J. Radiol., 19, 1 and 77.

Peacock, T. B. (1858). Malformations of the Heart, London.

Taussig, H. B. (1947). Congenital Malformations of the Heart, New York. 